\title{
Clinical Study of Postmenopausal Bleeding
}

\author{
Shahnaz Rahman ${ }^{1}$, TA Chowdhury ${ }^{2}$, Zinnat Ara Nasreen ${ }^{3}$ \\ Shahana Shermin ${ }^{4}$, Nahid Sultana ${ }^{5}$, Maherun Nessa ${ }^{6}$
}

\begin{abstract}
Background: Women with postmenopausal bleeding (PMB) should be thoroughly evaluated. A thorough examination may help in the diagnosis of vulval, vaginal, cervical or pelvic pathology. Objective: This study was carried out to find the probable causes in patients presenting with postmenopausal bleeding. Materials and method: This observational study included 50 women with postmenopausal bleeding and was conducted in the department of Obstetrics and Gynaecology of Bangladesh Institute of Research and Rehabilitation in Diabetes, Endocrine and Metabolic Disorder (BIRDEM) Hospital, Dhaka, Bangladesh, from January 2004 to December 2004. Transvaginal ultrasonogram (TVS), diagnostic curettage and cervical biopsy were done and histopathology report was collected. Results: The mean age of the patients was 57.74 years (range 48-75 years), and the median age of menopause was 50 years. Among the patients $18(36 \%)$ had only diabetes and $25(50 \%)$ patients had both diabetes and hypertension. Nineteen patients (38\%) were overweight, 5 patients (10\%) were obese and 2 (4\%) were morbidly obese. Per speculum examination revealed suspected cervical carcinoma in 5 cases (10\%) and cervical polyp in 1 case (2\%). The most common clinical finding was atrophy of the uterus and vagina in 26 patients (52\%). TVS revealed endometrial thickness of $5 \mathrm{~mm}$ or more in 17 cases $(37.7 \%)$ and $<5 \mathrm{~mm}$ in 26 cases (57.7\%). Nine patients (18\%) had carcinoma, 16 patients (32\%) had benign pathology and 19 (38\%) patients had endometrial atrophy on histology. Conclusion: A detailed history taking, thorough physical examination and relevant investigations can lead to a correct detection of cause of postmenopausal bleeding. Those who have normal adnexae and thin endometrium (endometrium $<5 \mathrm{~mm}$ ) may not need endometrial biopsy.
\end{abstract}

Keywords: Postmenopausal bleeding; clinical profile.

Delta Med Col J. Jul 2017;5(2):83 - 88

\section{Introduction}

The menopause constitutes a watershed in a total lifespan of women has gradually increased. woman's life that leads to profound changes in Women can now spend up to one-third of their several systems. The population is ageing as the lives after the menopause in a state of profound

1. Resident Surgeon, Dept. of Obstetrics \& Gynaecology, BIRDEM General Hospital, Dhaka, Bangladesh.

2. Professor \& Chief Consultant, Dept. of Obstetrics \& Gynaecology, BIRDEM General Hospital, Dhaka, Bangladesh.

3. Professor \& Head, Dept. of Obstetrics \& Gynaecology, ZH Sikder Women's Medical College, Dhaka, Bangladesh.

4. Senior Medical Officer, Dept. of Obstetrics \& Gynaecology, BIRDEM General Hospital, Dhaka, Bangladesh.

5. Associate Professor, Dept. of Obstetrics \& Gynaecology, BIRDEM General Hospital, Dhaka, Bangladesh.

6. Assistant Professor, Dept. of Obstetrics \& Gynaecology, BIRDEM General Hospital, Dhaka, Bangladesh.

Correspondence: Dr. Shahnaz Rahman. e-mail: skrafianoor@gmail.com 
oestrogen deprivation. Menopause is generally considered to have occurred retrospectively after one year of amenorrhoea and subsequently unscheduled vaginal bleeding must be regarded as an abnormality. Postmenopausal bleeding could represent signs of serious lesion such as squamous cell carcinoma or adenocarcinoma if not detected and managed early. ${ }^{1}$ So it should not be taken lightly.

Postmenopausal bleeding is a phenomenon of the Western world and is most common in Caucasian women of high socioeconomic class. The incidence increases with migration from developing to western countries, and implicates environmental reasons as the main cause. ${ }^{2}$ The disparity is probably due to the increased use of exogenous oestrogens, the higher degree of obesity and therefore, peripheral conversion of plasma androstenedione to oestrone, and a higher accessibility to medical services and therefore, increase in reporting. ${ }^{3}$

Approximately, 3-5\% of menopausal women suffer from this condition and require prompt and thorough evaluation. ${ }^{4,5}$ Thorough history taking and physical examination are integral part of diagnosis and results of investigations should only be interpreted with whole clinical picture. Nulliparity, late menopause and triad of obesity, hypertension and diabetes are considered to be risk factors towards the development of endometrial malignancy. ${ }^{2}$ Increased incidence of endometrial hyperplasia and carcinoma in women with unopposed exposure to either endogenous or exogenous oestrogen has been reported.6,7 In postmenopausal women, adipose tissue is the major conversion site of androstenedione to oestrone and increase with age and high body weight. The risk of endometrial cancer increases with age and the number of risk factors present. ${ }^{8}$ In one study, the risk was calculated to be as high as $87 \%$ in nulliparous, diabetic women over the age of 70 years compared to only $2.6 \%$ if none of the risk factors were present and the odds ratio for endometrial malignancy was 9.1 for women over 70 years, 3.7 for women with diabetes and 2.7 for nulliparous women. ${ }^{9}$

A thorough examination may help in the diagnosis of vulval, vaginal, cervical or pelvic pathology, such as cervical polyps, senile atrophic vaginitis or ulceration from a ring pessary may be directly visualized. Furthermore, an indication for patient's general health can be obtained, which is important before considering a general anaesthetic. The present study was carried out to find out the causes of postmenopausal bleeding.

\section{Materials and method}

This observational study was conducted in the Department of Obstetrics and Gynaecology of Bangladesh Institute of Research and Rehabilitation in Diabetes, Endocrine and Metabolic Disorder (BIRDEM) Hospital, Dhaka, Bangladesh, from January 2004 to December 2004. A total of 50 menopausal women admitted in Gynaecology department because of per vaginal bleeding were included in this study purposively. Menopause is defined as permanent cessation of menstruation for at least one year at the end of reproductive life. Postmenopausal bleeding after taking hormone replacement therapy for vasomotor symptoms or women who had undergone subtotal hysterectomy was excluded from this study.

A detailed history was taken and findings were noted in predesigned case record form. In the history emphasis was given on patient's age, socioeconomic status, the interval between menopause and the onset of abnormal vaginal bleeding, obstetric history, pharmacological therapy and family history of malignancy. After interviewing the patient the investigator examined the patient with the consent taken earlier. 
Examination of the patient included general examination, measurement of height and weight. Abdominal examination was done in order to find out abnormal lump. Per speculum examination was done to see any visible lesion like ulceration or growth in the cervix or vagina. Bimanual examination was done to delineate the size of the uterus and its consistency and also exclude other pelvic pathology.

Transvaginal ultrasonogram (TVS) was done in 44 cases to see the endometrial thickness and other pelvic pathology like ovarian tumour. Routine investigation for general anaesthesia fitness was done in all cases. Diagnostic curettage and cervical biopsy was done and histopathology report was collected.

\section{Results}

The study was carried out among 50 patients complaining of postmenopausal bleeding. The mean age of the patients was 57.74 years (range 48-75 years), and the median age when menopause occurred was 50 years (not shown in the table). One patient was nulliparous, and 30 patients $(60 \%)$ had 5 or more children. Among 50 patients, $3(6 \%)$ were found to have endometrial carcinoma. The pattern was 1 (2\%) nulliparous, 1 ( $2 \%)$ had one child and last one had 3 children. Eighteen patients (36\%) were in good socioeconomic condition, 23 patients (46\%) were in average socioeconomic condition and 9 patients $(18 \%)$ were in poor socioeconomic condition. In 24 patients (48\%) BMI were within acceptable range $\left(18.5-24 \mathrm{~kg} / \mathrm{m}^{2}\right), 19$ patients $(38 \%)$ were overweight $\left(25-29.9 \mathrm{~kg} / \mathrm{m}^{2}\right)$, only 5 patients $(10 \%)$ were obese $\left(30-39.9 \mathrm{~kg} / \mathrm{m}^{2}\right)$ and $2(4 \%)$ patients were morbidly obese $\left(>40 \mathrm{~kg} / \mathrm{m}^{2}\right)$ (Table I).
Table I: Demographic characteristics of study subjects $(\mathbf{N}=\mathbf{5 0})$

\begin{tabular}{lcc}
\hline Variables & Frequency & Percentage \\
\hline Age group (years) & 3 & \\
$<50$ & 15 & 6.0 \\
$50-54$ & 12 & 30.0 \\
$55-59$ & 10 & 24.0 \\
$60-64$ & 7 & 20.0 \\
$65-69$ & 2 & 14.0 \\
$70-74$ & 1 & 4.0 \\
$>74$ & & 2.0 \\
Parity & 1 & \\
0 & 4 & 2.0 \\
$1-2$ & 15 & 8.0 \\
$3-4$ & 30 & 30.0 \\
$\geq 5$ & & 60.0 \\
BMI (kg/m ${ }^{2}$ ) & 24 & \\
Normal & 19 & 48.0 \\
Overweight & 5 & 38.0 \\
Obese & 2 & 10.0 \\
Morbidly obese & & 4.0 \\
Socioeconomic condition & 18 & \\
Good & 23 & 36.0 \\
Average & 9 & 46.0 \\
Poor & & 18.0 \\
Marital status & 1 & 2.0 \\
Unmarried & 30 & 60.0 \\
Married & 19 & 38.0 \\
Widow & & \\
\hline
\end{tabular}

Among the study subjects 21 patients (42\%) came with postmenopausal bleeding for 1-3 months, 3 patients $(6 \%)$ came with bleeding for more than 6 months. In most cases duration of bleeding was between 1-3 months. Most (36\%) of the patients in this study were diabetic and 50\% patients had both diabetes and hypertension. Relevant clinical information is shown in Table II.

Table II: Clinical information of study subjects ( $\mathrm{N}=\mathbf{5 0})$

\begin{tabular}{lcc}
\hline Parameters & Frequency & Percentage \\
\hline Interval between menopause $\&$ & & \\
PMB (years) & 17 & 34.0 \\
$\quad<5$ & 18 & 36.0 \\
$5-10$ & 15 & 30.0 \\
$>10$ & & \\
Duration of bleeding (months) & 10 & 20.0 \\
$<1$ & 21 & 42.0 \\
$1-3$ & 16 & 32.0 \\
$4-6$ & 3 & 6.0 \\
$>6$ & & \\
*Associated medical disorder & 18 & 36.0 \\
Diabetes mellitus & 2 & 4.0 \\
Hypertension & 25 & 50.0 \\
Diabetes and hypertension & 1 & 2.0 \\
Anaemia & 1 & 2.0 \\
Chronic liver disease & 2 & 4.0 \\
Hypothyroidism & & \\
\hline
\end{tabular}

* Multiple responses 
Per abdominal examination did not reveal any abnormality. Inspection on per vaginal examination did not reveal any abnormality in the vulva, urethra, perineum, and anus. Per speculum examination revealed suspected cervical carcinoma in 5 cases $(10 \%)$, cervical polyp in 1 case $(2 \%)$ and vaginal atrophy in 26 cases $(52 \%)$. Bi manual examination revealed small size (atrophy) uterus in 26 patients (52\%), normal size uterus in 14 patients $(28 \%)$, and 8 patients $(16 \%)$ had 6-8 weeks size uterus. Ovaries were not palpable in any of the patients. (Table III)

Table III: Physical findings of study subjects ( $\mathbf{N}=\mathbf{5 0})$

\begin{tabular}{lcc}
\hline Findings & Frequency & Percentage \\
\hline Per speculum examination & & \\
*Cervix & 26 & 52.0 \\
$\quad$ Flushed & 16 & 32.0 \\
$\quad$ Normal & 4 & 8.0 \\
Hypertrophied & 1 & 2.0 \\
$\quad$ Cervical polyp & 5 & 10.0 \\
$\quad$ Growth & & \\
*Vagina & 26 & 52.0 \\
$\quad$ Atrophy & 3 & 6.0 \\
$\quad$ Senile vaginitis & 24 & 48.0 \\
$\quad$ Normal & & \\
Bimanual examination & & \\
Size of uterus & 26 & 52.0 \\
$\quad$ Atrophy & 14 & 28.0 \\
$\quad$ Normal & 8 & 16.0 \\
6-8 weeks & 2 & 4.0 \\
$\quad$ 9-10 weeks & & \\
* Multiple responses & &
\end{tabular}

Table IV shows the TVS findings. TVS reports were available in 44 cases. Among them endometrial thickness $5 \mathrm{~mm}$ or more was found in 16 cases $(36.36 \%)$ and $<5 \mathrm{~mm}$ in 26 cases $(59.09 \%)$. Ovarian tumour/cyst was found in 2 cases $(4.55 \%)$ of which one was mucinous cystadenoma and one was serous cystadenoma.

Table IV: TVS findings of study subjects $(n=44)$

\begin{tabular}{lcc}
\hline *Findings & Frequency & Percentage \\
\hline Size of uterus & & \\
$\quad$ Small size & 26 & 59.09 \\
$\quad$ Normal size & 8 & 18.18 \\
6-8 weeks & 8 & 18.18 \\
9-10 weeks & 2 & 4.55 \\
Endometrial thickness (mm) & & \\
$\quad<5$ & 26 & 59.09 \\
$\geq 5$ & 16 & 36.36 \\
Endometrial polyp & 2 & 4.55 \\
Endometrial collection & 3 & 6.82 \\
Ovary & & \\
$\quad$ Tumour & 2 & 4.55 \\
$\quad$ Normal & 42 & 95.45 \\
\hline
\end{tabular}

* Multiple responses
Histopathology findings revealed that 16 patients (32\%) had benign pathology, 9 (18\%) patients had carcinoma, and 19 (38\%) patients had endometrial atrophy.

\section{Table V: Histopathological findings $(\mathrm{N}=\mathbf{5 0})$}

\begin{tabular}{lcc}
\hline *Findings & Frequency & Percentage \\
\hline Endometrial carcinoma & 3 & 6.0 \\
Cervical carcinoma & 6 & 12.0 \\
Total carcinoma & 9 & 18.0 \\
Benign ovarian tumour & 2 & 4.0 \\
Adenomatous & & \\
endometrial hyperplasia & 1 & 2.0 \\
Atypical endometrial hyperplasia & 1 & 2.0 \\
Simple hyperplasia & 2 & 4.0 \\
Proliferative endometrium & 2 & 4.0 \\
Endometrial polyp & 6 & 12.0 \\
Cervical polyp & 1 & 2.0 \\
Cervical dysplasia (CIN III) & 1 & 2.0 \\
Benign pathology & 16 & 32.0 \\
Endometrial atrophy & 19 & 38.0 \\
Insufficient endometrial sample & 6 & 12.0 \\
\hline * Multiple responses & &
\end{tabular}

\section{Discussion}

The presents study revealed that incidence of postmenopausal bleeding (PMB) was common in the 5 th to 7 th decades of life. Similar finding was observed in the studies by carlos et al., Gredmark et al. and Goldstein et al. 5,8,10 Earlier studies reported that the incidence of postmenopausal bleeding decreases with increasing age and this trend was also similar in our study. 4,8

Though in our series only $10 \%$ subjects were obese and $4 \%$ were morbidly obese, several other studies concluded that increased body mass index is a risk factor for development of pathological changes in endometrium, which could lead to postmenopausal bleeding. ${ }^{9}$ The cause of less number of obese patients may be due to the difference between the socio economic condition and lifestyle between our population and Western women.

It is evidence based that PMB is associated with diabetes, hypertension and obesity and these are independent risk factors for endometrial carcinoma. ${ }^{5}$ In this study, $50 \%$ of PMB patients had multiple medical disorders, like diabetes and 
hypertension which is similar to others' observation. ${ }^{5,11}$

Most of the studies, like Gusberg ${ }^{2}$ reflect the incidence of PMB is high in affluent society but incidence of PMB in this study was high in an average economic group. Hormone replacement therapy is the commonest cause of PMB and it is commonly used by affluent society. In this study PMB after taking exogenous oestrogen was excluded.

In this study, evidence of atrophy was found clinically as well as histopathologically. Physical examination of PMB patients in this study showed that 26 cases $(52 \%)$ had small sized uterus with flushed cervix and atrophied vagina. Regarding endometrial histology, 19 patients (38\%) had endometrial atrophy and 6 samples $(12 \%)$ were insufficient to evaluate pathology. Several studies showed atrophic endometrium and atrophic vaginitis as the commonest cause of PMB. 5,8

In the present study on per speculum examination, cervical carcinoma was suspected in 5 cases $(10 \%)$. But in a study Gredmark et al. found cervical carcinoma in 6 out of 457 PMB cases. ${ }^{8}$

An advantage of ultrasound for investigating PMB is the opportunity for examination of the whole pelvis. In this study 2 patients (4\%) had ovarian tumours (one was mucinous cystadenoma and another was serous cystadenoma) which were diagnosed by TVS. Gredmark et al. found that 8 cases (1.7\%) of 457 PMB had ovarian tumours. ${ }^{8}$ As many ovarian cancers cannot be palpated on bimanual examination, ultrasound is an important investigation.

Postmenopausal bleeding is more likely to be caused by pathologic disease than is bleeding in younger women. In the present series, 9 patients (18\%) had malignancy, including endometrial carcinoma $3 \%$ and cervical carcinoma 6\%, 16 patients $(32 \%)$ had benign pathology and 19 patients $(38 \%)$ had endometrial atrophy. Gredmark et al. reported almost similar findings. ${ }^{8}$

\section{Conclusion}

Clinical examination of PMB patients in this study showed that 26 cases (52\%) had small sized uterus with flushed cervix and atrophied vagina and histologically endometrium was atrophic in 19 cases $(38 \%)$. Two patients had ovarian tumours which were diagnosed by TVS. So TVS should be included in the evaluation of PMB to find out the pathology outside the uterus and also to see the endometrial thickness. A recent study reported a $0.6 \%$ prevalence of endometrial cancer in women with PMB and endometrial thickness $<4 \mathrm{~mm}$. This prevalence increased to $19 \%$ in women with an endometrial thickness $\geq 5 \mathrm{~mm}$. The authors concluded that in women with an endometrial thickness $<4 \mathrm{~mm}$, endometrial biopsy is not required. ${ }^{12-14}$

\section{References}

1. Bricat M. Baron YM, Galea R. The Menopause. In: Shaw RW, Soutter WP, Stanton SL, editors. Gynaecology. 2nd ed. Edinburgh: Churchill Livingstone; 1997. p.373.

2. Gusberg SB. The Individual at High Risk for Endometrial Carcinoma. Am J Obstet Gynecol. 1976;126:535-42.

3. MacDonald PC, Edman CD, Hemsell DL, Porter JC, Siiteri PK. Effect of Obesity on Conversion of Plasma Androstenedione to Estrone in Post-Menopausal Women with and without Endometrial Cancer. Am J Obstet Gynecol. 1978;130:448-55.

4. Singh P, Dwivedi P, Mendiratta S. Correlation of Endometrial Thickness with the Histopathological Pattern of Endometrium in Postmenopausal Bleeding. J Obstet Gynaecol India. 2016;66(1):42-46.

5. Carlos RC, Bree RL, Abrahamse PH, Fendrick AM. Cost Effectiveness of Saline Assisted Hysterosonography and Office Hysteroscopy in the Evaluation of Postmenopausal Bleeding. Acad Radiol. 2001;8:835-44. 
6. Nisker JA, Hammond GL, Davidson BJ. Serum Sex Hormone-Binding Globulin Capacity and the Percentage of Free Estradiol in Postmenopausal Women with or without Endometrial Carcinoma. Am J Obstet Gynecol.1980;138:637-42.

7. Oettinger M, Samberg I, Levitan Z, Eibschitz I, Sharf M. Hormonal Profile of Endometrial Cancer. Gynecol Obstet Invest. 1984;17(5):225-35.

8. Gredmark T, Kvint S, Havel G, Mattson LA. Histopathological Findings in Women with Postmenopausal Bleeding. Br J Obstet Gynaecol. 1995;102:133-36.

9. Feldman S, Cook EF, Harlow BL, Berkowitz RS. Predicting Endometrial Cancer among Older Women who Present with Abnormal Vaginal Bleeding. Gynecol Oncol. 1995;56:376-81.

10. Mandić A, Gutić B, Kapicl-Ivković T, Mladenović LS, Kaćanski MM. Clinical and Histopathological Characteristics in Patients with Postmenopausal Bleeding. Arch Oncol. 2013;21(1):5-10.
11. Rekha B, Rani AS. An Analysis of Histopathological Findings in Women with Postmenopausal Bleeding in a Tertiary Care Hospital. IOSR-JDMS 2016;15(9):1-12

12. Granberg S, Wikland M, Karlsson B, Norstrbm A, Friberg LG. Endometrial Thickness as Measured by Endovaginal Ultrasonography for Identifying Abnormality. Am J Obstet Gynecol. 1991;164:47-52.

13. Gull B, Carlsson S, Karlsson B, Ylostalo P, Milsom I, Granberg S. Transvaginal Ultrasonography of the Endometrium in Women with Postmenopausal Bleeding. Is It Always Necessary to Perform an Endometrial Biopsy? Am J Obstet Gynecol. 2000;182:509-15.

14. Gull B, Karlsson B, Milsom I, Granberg S. Can Ultrasound Replace Dilation and Curettage? A Longitudinal Evaluation of Postmenopausal Bleeding and Transvaginal Sonographic Measurement of the Endometrium as Predictors of Endometrial Cancer. Am J Obstet Gynecol. 2003;188(2):401-408. 